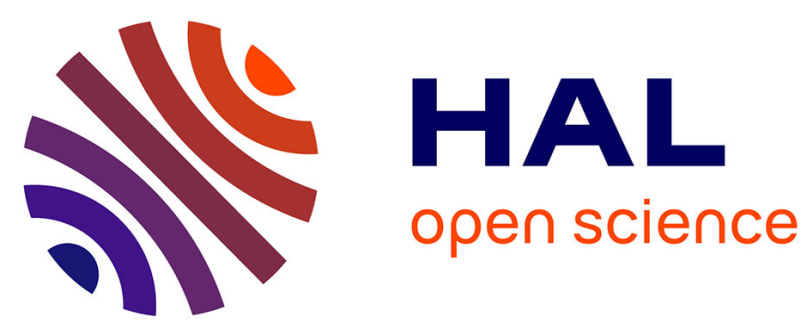

\title{
Is Ecosystem Health a Useful Metaphor? Towards a Research Agenda for Ecosystem Health Research
}

\author{
Sami Hyrynsalmi, Matti Mäntymäki
}

\section{To cite this version:}

Sami Hyrynsalmi, Matti Mäntymäki. Is Ecosystem Health a Useful Metaphor? Towards a Research Agenda for Ecosystem Health Research. 17th Conference on e-Business, e-Services and e-Society (I3E), Oct 2018, Kuwait City, Kuwait. pp.141-149, 10.1007/978-3-030-02131-3_14 . hal-02274194

\section{HAL Id: hal-02274194 \\ https://hal.inria.fr/hal-02274194}

Submitted on 29 Aug 2019

HAL is a multi-disciplinary open access archive for the deposit and dissemination of scientific research documents, whether they are published or not. The documents may come from teaching and research institutions in France or abroad, or from public or private research centers.
L'archive ouverte pluridisciplinaire HAL, est destinée au dépôt et à la diffusion de documents scientifiques de niveau recherche, publiés ou non, émanant des établissements d'enseignement et de recherche français ou étrangers, des laboratoires publics ou privés. 


\title{
Is Ecosystem Health a Useful Metaphor? Towards a research agenda for ecosystem health research
}

\author{
Sami Hyrynsalmi ${ }^{2}$ and Matti Mäntymäki ${ }^{1}$ \\ ${ }^{1}$ University of Turku, Turku, Finland \\ matti.mantymaki@utu.fi \\ ${ }^{2}$ Pervasive Computing, Tampere University of Technology, Pori, Finland \\ sami.hyrynsalmi@tut.f
}

\begin{abstract}
The term ecosystem has been widely adopted outside its original domain in biology, for example in business and engineering studies. Ecosystem health is a derivative metaphor used to describe the success of the ecosystem. In this paper, we describe the key shortcomings of ecosystem health research. We put forward two key postulates of ecosystem health. Based on these postulates we present a research agenda for ecosystem health.
\end{abstract}

Keywords: business ecosystem, software ecosystem, ecosystem health

\section{Introduction}

The term 'ecosystem' has been widely adopted outside its original domain in biology, for example in business and engineering studies. Prior studies have introduced terms including 'business ecosystems' (Peltoniemi \& Vuori 2004), 'innovation ecosystems' (Oh et al. 2016), 'mobile application ecosystems' (Hyrynsalmi et al. 2016), 'service ecosystems' (Vargo \& Lusch 2011), 'product ecosystems’ (Frels et al. 2003), among others. The widespread use implies that the ecosystem analogy has been viewed to provide value-added for research. At the same time, the use of ecosystem analogy has also been criticized (see for example Oh et al. 2016; Hyrynsalmi et al. 2015a, Mäntymäki \& Salmela 2017).

In biology, an ecosystem, or ecological system, typically denotes a unit of biological organization made up of all the organisms in a given area, thus forming a "community". Organisms within a community interact with the physical environment so that the flow of energy leads to characteristic trophic structure and material cycles within the system (Odum 1966). Ecosystem health is an analogy used to describe business ecosystems. According to Ianisiti and Levien (2004a, p. 5), ecosystem health is a crucial concept in business ecosystem research: "if the ecosystem is healthy, 
individual participants will thrive; if the ecosystem is unhealthy, individual participants will suffer".

Up to date, with one notable exception (Hyrynsalmi et al. 2018), very few studies have critically evaluated applicability of the ecosystem health analogy outside the biological domain, for example with respect to business or software. To address this void in prior literature, this study aims to concretize the critique presented by Hyrynsalmi et al. (2018) towards a research agenda. As a result, the purpose of this paper is to $i$ ) critically discuss the applicability of the ecosystem health analogy in business research, ii) address the key challenges related to the use of the ecosystem health analogy, and iii) put forward a research agenda to address these challenges.

The remaining of the study is structured as follows. Section 2 previews the extant literature on software ecosystem health. Section 3 defines the starting hypotheses and drivers for the ecosystem health research renewal. In addition, it discusses on various countermeasures against the seen issues. Section 4 lists the research actions proposed and Section 5 concludes the study.

\section{Ecosystem health as a metaphor}

In addition to different biology inspired analogies such as rainforest or jungle, research on business networks has used the 'business ecosystem' analogy by Moore (1993, 1996), and its derivatives — such as 'software ecosystem'—as a crucial conceptualizations for today's business networks. A key characteristic that distinguishes natural ecosystems from artificial ecosystems such business ecosystems is actor's consciousness of the existence of the ecosystem and the actors involved in the ecosystem ecosystems (Moore 1993). The fact that actors are conscious of the ecosystem allows then to also evaluate the health of the ecosystem and adapt their behaviour intentionally.

In this paper, we view software ecosystem as a subset of the more generic business ecosystem concept (Hyrynsalmi, Seppänen, Nokkala, Suominen, \& Järvi, 2015a). There are several different kinds of software ecosystems (SECO) focusing on the software producing companies and their networks (Jansen et al 2009, Manikas \& Hansen 2013a), mobile ecosystems formed by the companies producing hardware and software for new era smartphones (Basole 2009), and even mobile application ecosystems comprise the relationships of mobile application marketplaces, their content producers i.e. application developers, and users (Hyrynsalmi et al 2014). Furthermore, the software ecosystem concept includes non-commercial open-source ecosystems built on shared code repositories (e.g., OSGi ecosystem), commercial open-source projects (e.g., WebKit) as well as platform ecosystems revolve around global players such as Amazon, Facebook, and Alibaba and utilize the focal company's interface to customers and brand.

To illustrate the difference between business and software ecosystem, Manikas and Hansen (2013) pointed out that in a software ecosystem, the relationships between the actors are based on a shared software technology or a software platform (Manikas \& Hansen 2013a). Based on these considerations, we conceptualize, software 
ecosystems are business ecosystems where software constitutes a focal part of the unit of exchange.

Software ecosystem as research area is relatively young, first publications dating back to the first decade of the 2000s (Jansen \& Cusumano, 2013). The term and conceptualization emanate from Moore's $(1993,1996)$ work on business ecosystems. According to Moore (1993), a business ecosystem is a complex network of organizations and individuals that are involved in the creation or delivery of a service or a product. The business ecosystem concept has hitherto become critical for both scholars as well as for practitioners to understand and describe today's business networks. Due to the potentially simultaneous cooperation and competition as well as abundance of organizations involved in the network (cf. Mäntymäki \& Salmela 2017; Hyrynsalmi et al. 2017), business ecosystem are often complex systems.

It is not surprising that business ecosystems are nowadays seen everywhere, from retail (Moore 1993) to telecommunication (Basole 2009), and from small ecosystems orchestrated by a single company to massive software-based value-chains consisting of hundreds of thousands of independent vendors (Hyrynsalmi 2014). According to Moore (1993) a key characteristic of a business ecosystem is the survival of an individual actor depends on the whole network. The survival of the ecosystem is turn contingent upon the individual actors' own choices and agency (Moore 1993). Since then, the literature has examined and put forwards conceptualizations for the wellbeing of business ecosystems (e.g. Iansiti and Levien 2004a, 2004b; Hyrynsalmi et al 2015, da Silva Amorim et al. 2017, Alves, Oliveira, and Jansen 2018).

Iansiti \& Levien (2004a) derived three health measures from biological ecosystems for business ecosystems: productivity, robustness to external shocks, and niche creation that helps the ecosystem to renew. Iansiti and Levien are (2004a) describe these three measures as follows:

Productivity of business ecosystems can be measured as e.g. return on capital invested or economic value-added created from tangible and intangible assets in producing goods or services. This refers to a biological ecosystem's ability e.g. create biomass from inputs such as sunlight.

Robustness, in its simplest form, refers to the survival rate of ecosystem's members, either in relation to other ecosystems or over time. Robustness means that the ecosystem can face and survive from the changes of the environment.

Niche Creation in the context of business ecosystems refers to ability to create value by putting new functions into operation and increasing meaningful diversity in ecosystem through that. Diversity gives ecosystem potential for productive innovation and indicates its ability to absorb shocks from outside.

In his analysis of ecosystem health literature, Jansen (2014) noted the lack of operationalisations for ecosystem health. To address this issue, Jansen (2014) presented the OSEHO, a health model for open-source ecosystems. It is based on health characteristics defined by Iansiti and Levien (2004a). However, while Jansen's approach is holistic, the model is only applicable for the open-source software ecosystem and thus it cannot be used to evaluate the multitude of different types of software ecosystems. 
Ben Hadj Salem Mhamdia (2013) extended the Iansiti's and Levien's (2004a) model and measured the health of an ecosystem with robustness, productivity, interoperability, satisfaction of stakeholders and creativity. However, the model is built on an interpretation that only firms located in the same country would create a business ecosystem or a software ecosystem. Similarly, den Hartigh, Tol and Visscher (2006) presented a model and measured well-being of an ecosystem based on their colocation in the same country. These interpretations and measures presented for the health of an ecosystem are not compatible with the more traditional interpretation where businesses are required to cooperate instead of being nearly located.

In addition, Hyrynsalmi et al. (2015) as well as Manikas and Hansen (2013b) have presented models for ecosystem health assessment. Hyrynsalmi et al. (2015) adapted a process-like view on ecosystem health assessment. However, the work is based on summarizing extant literature and did not presented any empirical validation to support the models.

Manikas and Hansen (2013b) divided software ecosystem health into three components: the health of software, actors and orchestration. This approach diverges from other conceptualizations and thus provides a novel perspective to study ecosystem health but lacks operationalization and thus also empirical validation. Furthermore, the model measures the health of software through the healthiness of components and platforms. However, instead of a shared platform, software ecosystem can be based on a common standard (cf. Jansen \& Cusumano 2013, Knodel \& Manikas 2015).

Finally, some existing critique have presented towards the current models. For example, Hyrynsalmi (2016) presented a critique towards unclear terminology and required redefining the concept. Hyrynsalmi, Ruohonen and Seppänen (2018) continue the critique by noting that $i$ ) it is not clear for whom ecosystem health measures are meant to (e.g., should they be used by ecosystem orchestrators or customers), ii) whether the measures are proactive or only reactive, and iii) emphasizing that the natural evolution of an ecosystem (c.f. Plakidas et al 2016, Teixeira et al 2017) has not been taken into account in most of the ecosystem health metrics. However, neither of those works proposed any concrete steps to improve the current status quo.

\section{$3 \quad$ Key shortcomings of prior ecosystem health literature}

In this section, we elaborate on the key issues related to ecosystem health that, in our view, prior research has not sufficiently addressed. To this end, we put forward two key postulates of ecosystem health.

Key postulate 1: Due to the scattered use of the terms 'ecosystem' and 'ecosystem health' both concepts have become muddled and meaningless.

The concepts business ecosystem and business ecosystem health are often used as labels for systems or networks under empirical investigation without sufficient consideration and argumentation whether the entity under investigation is an ecosystem. With respect to this issue, Hyrynsalmi et al. (2015) claim that after the 
labelling has been done, the ecosystem or ecosystem health aspect is often forgotten. This in turn has led to a situation where a multitude of easy-to-collect measures are proposed for assessing the ecosystem health. Thus, in the current discourse, a very diverse set of entities are labelled and empirically treated as ecosystems. Consequently, more or less every aspect of the so-called ecosystem can be used to measure ecosystem health. (Hyrynsalmi et al 2015b, Seppänen et al. 2017.)

As an example of the easy-to-collect measures for ecosystem health, a number of prior studies have proposed using lines of code as a productivity measure of a software ecosystem (cf. Hyrynsalmi 2014 for a summary). However, the number of code lines has been considered an insufficient metric of productivity for decades (Jones 2000). For example, comparing different programming languages is hard and work needed to write a single line of code varies a lot between different kinds of tasks as well as environments. Moreover, productivity should capture an ecosystem's ability to "transform technology and other raw materials of innovation into lower costs and new products" (Iansiti \& Levien 2004a, p. 3). It is thus questionable whether the number of source code lines meaningfully captures the productivity of an ecosystem.

To address these issues, we hold it is important to move towards establishing a baseline for ecosystem health, i.e. defining what being healthy means in the context of software ecosystems. A potential step to this direction would be to study major software ecosystems - such as Google Play ecosystem and Symbian ecosystem - that exist currently and have already become extinct. The extant literature has focused only on the existing software ecosystems and omitted the studies of departed ecosystems, i.e. ecosystem post-mortems (c.f. Hyrynsalmi et al 2015a, da Silva Amorim et al 2017). This could potentially help better understand what health means and whether absence of health leads into ecosystem death.

Key postulate 2: Existing frameworks to analyse software ecosystem health have been designed to describe certain ecosystem sub-types but have limited value for identifying general properties of business or software ecosystems.

According to (Hyrynsalmi et al 2015a), current research has treated different software ecosystems as a homogenous group and omitted the rich diversity of different ecosystem types. For example, when Wnuk et al. (2014) tested the ecosystem health framework by Jansen (2014), they used a tool designed for general type open-source ecosystems while their case study focused on a hardware-dependent software ecosystem.

\section{Towards a research agenda for software ecosystem health}

In this section, we build on our two key postulate and move towards putting forward a research agenda for software ecosystem health. To this end, we describe four directions for future research activities.

Study of extinct and dying ecosystems. We propose future research taking a lifecycle perspective to ecosystem health. While there are studies analysing the reasons for the fall of the Symbian mobile ecosystem (e.g. West \& Wood, 2013), there is a lack of research examining specifically how ecosystem health measures evolved 
during the ecosystem life. To address this void, future research could look into other ecosystems potentially approaching the terminal stage and examine how the situation look like through the current measures of ecosystem health and what kind of weak signals, if any, might predict the decline of an ecosystem. This type of research could be conducted e.g. with case study methodology.

Study of healthy ecosystems. We propose an analysis of software ecosystems that are in the different phases of their lifecycles while still considered to be growing. The focus of the research is specifically on existing health measures as well as identifying signals, incidents, and contingencies that may predict the success of an ecosystem. This would

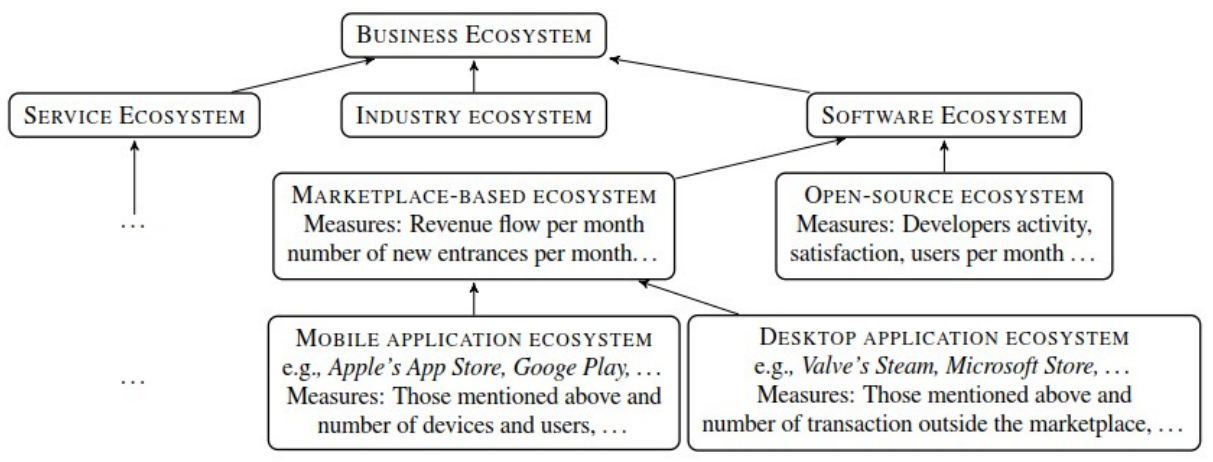

$\square$ Fig. 1. A partial, simplified, example of an ecosystem taxonomy.

help to create a more comprehensive picture of the usefulness of different ecosystem health metrics. In addition, by combining the results of this line of inquiry with insights from the studies of extinct ecosystems, it would be possible to evaluate the usability and relevance of different metrics in different stages of ecosystem lifecycle.

Conceptualization of ecosystem health. We propose conceptual research focusing on ecosystem health. As pointed out by Hyrynsalmi et al. (2015, 2018), there is an evident need for increased conceptual clarify with respect to business ecosystems and ecosystem health.

Ecosystem taxonomy construction. As discussed in Section 3, we propose building a general business ecosystem taxonomy. This would help to make sense in the vast field of ecosystems as well as to characterize relationships and connections between different types of ecosystems. The underlying idea behind the taxonomy is that that there are certain characteristics that are similar between certain types of ecosystems. Thus, by creating the ecosystem taxonomy and identifying measures that can be applied to study the health of different ecosystems, the taxonomy could help select the most usable health measures for each type of ecosystem. Figure 1 below provides an illustrative example of an ecosystem taxonomy.

Figure 2 summarizes the proposed research lines as well as their expected impacts to the redefining the field of ecosystem health research. The present study is subject to a number of threats. First, it is possible that each ecosystem should be treated as a snowflake. That is, each ecosystem is unique enough that no common characteristics 
can be identified. Keeping in mind that there is a limited number of ecosystems available - and the number of competitive ecosystems that a single market support is limited (Hyrynsalmi, Suominen, \& Mäntymäki 2015) plausibility of the snowflake hypothesis needs to be carefully evaluated.

Second, it is not clear whether the current or even new metrics have predictive or only explanatory value. That is, software ecosystem metrics might turn out to be useful

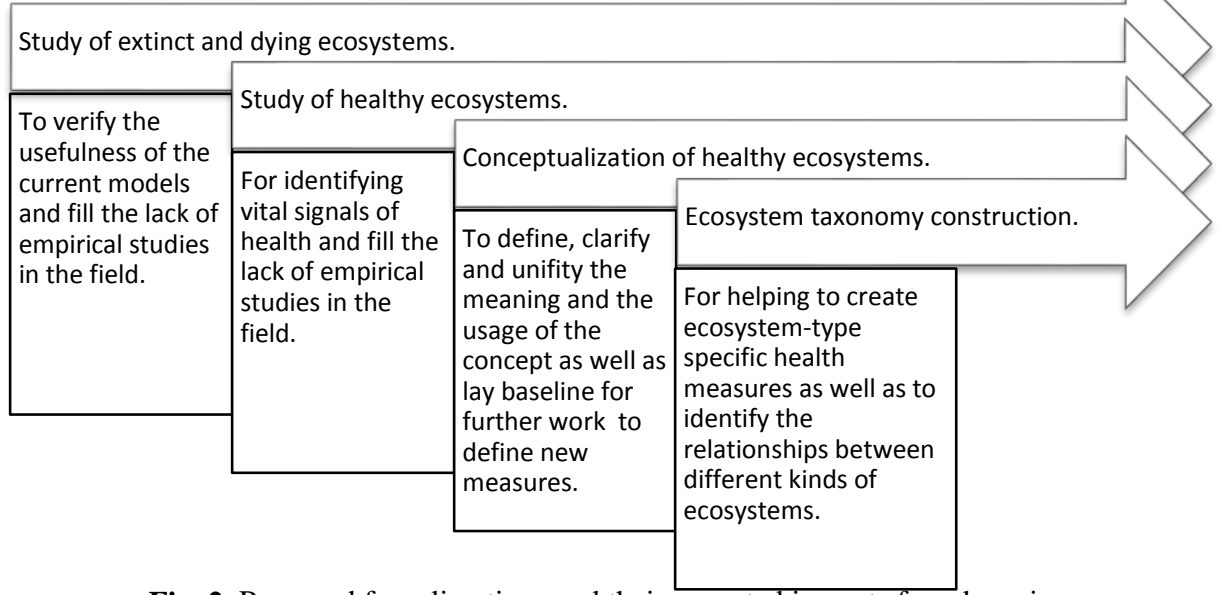

Fig. 2. Proposed four directions and their expected impacts for advancing ecosystem health research.

tools for explaining the past issues but lack have predictive power to evaluate the possible future development. Therefore, it is important for the ecosystem health research field to focus also on empirical studies exploring the limits of different metrics.

\section{Conclusions}

This study has presented two key postulates of ecosystem health research and put forward a research agenda to study ecosystem health. To this end, we have put forward two key postulates:

- \#1: Due to the scattered use of the terms 'ecosystem' and 'ecosystem health' both concepts have become muddled and meaningless, and

- \#2: Existing frameworks to analyse software ecosystem health have been designed to describe certain ecosystem sub-types but have limited value for identifying general properties of business or software ecosystems.

In addition, based on those two postulates, we proposed four research directions that should be advanced in order to restart ecosystem health research. Our points of departure to the most of the previous studies are our proposals to focus on ecosystemtype specific health measures, and to study also extinct ecosystems. The former would 
help us to define better-fitting measures for a case at hand. The latter would help us to evaluate whether the proposed measures are useful for predicting the future development and forecasting the fate of an ecosystem based on the health measures.

\section{References}

1. C. Alves., J. Oliveira., S. Jansen. Understanding Governance Mechanisms and Health in Software Ecosystems: A Systematic Literature Review. In: Enterprise Information Systems. ICEIS 2017. Lecture Notes in Business Information Processing, vol 321. Springer, Cham, 2018

2. S. da Silva Amorim, F. S. S. Neto, J. D. McGregor, E.S. de Almeida, G. von Flach, and C. Chavez. How Has the Health of Software Ecosystems Been Evaluated? A Systematic Review. In Proceedings of the 31st Brazilian Symposium on Software Engineering, 14-23, ACM, 2017.

3. R. C. Basole. Visualization of interfirm relations in a converging mobile ecosystem. Journal of Information Technology, 24(2):144-159, 2009.

4. A. Ben Hadj Salem Mhamdia. Performance measurement practices in software ecosystem. International Journal of Productivity and Performance Management, 62(5):514-533, 2013.

5. J. Frels, T. A. Shervani, and R. K. Srivastava. The Integrated Network Model: Explaining Resource Allocations in Network Markets. Journal of Marketing, 67(1):29-45, 2003.

6. den Hartigh, E., Tol, M., Visscher, W.: The health measurement of a business ecosystem. In: van Eijnatten, F.M. (ed.) Proceedings of the ECCON 2006 Annual Meeting: “Organisations as Chaordic Panarchies" - Towards Self-Transcending Work Holarchies, Bergen aan Zee, The Netherlands, European Network on Chaos

7. and Complexity Research and Management Practice, pp. 1-39 (2006)

8. S. Hyrynsalmi. Letters from the War of Ecosystems - An Analysis of Independent Software Vendors in Mobile Application Marketplaces. University of Turku, Finland, 2014. TUCS Diss. No 188.

9. S. Hyrynsalmi, M. Seppänen, and A. Suominen. Sources of value in application ecosystems. The Journal of Systems and Software, 96:61-72, 2014.

10. S. Hyrynsalmi, M. Seppänen, T. Nokkala, A. Suominen, and A. Järvi. Wealthy, healthy and/or happy - what does 'ecosystem health' stand for? In Software Business - 6th International Conference, ICSOB 2015, Braga, Portugal, June 10-12, 2015, Proceedings, 272- 287. Springer International Publishing, 2015a.

11. S. Hyrynsalmi, A. Suominen, and M. Mäntymäki. The role of developer multi-homing and keystone developers in mobile ecosystem competition. In Academy of Management Proceedings 2015, volume 1, 14157, 2015b.

12. S. Hyrynsalmi, A. Suominen, and M. Mäntymäki. The influence of developer multihoming on competition between software ecosystems. Journal of Systems and Software, 111, 119127, 2016

13. Hyrynsalmi, S. To Redefine Ecosystem Health, or not to Redefine? A view of scientific knowledge on the "software ecosystem health" concept. Proceedings of the European Workshop on Software Ecosystems 2015, 47-51, 2016

14. S. Hyrynsalmi, M. Mäntymäki, and A. W. Baur. Multi-homing and software firm performance - towards a research agenda. In Proceedings Digital Nations - Smart Cities, Innovation, and Sustainability. I3E 2017, 442-425. Lecture Notes in Computer Science, vol 10595. Springer, Cham. 2017

15. S. Hyrynsalmi, J. Ruohonen, M. Seppänen, M. Healthy until otherwise proven: some proposals for renewing research of software ecosystem health. In Proceedings of the first software health workshop, ACM, 2018 
16. M. Iansiti and R. Levien. The Keystone Advantage: What the New Dynamics of Business Ecosystems Mean for Strategy, Innovation, and Sustainability. Harvard Business School Press, USA, 2004a.

17. M. Iansiti and R. Levien. Strategy as ecology. Harvard Business Review, 82(3):68-78, 2004b.

18. S. Jansen. Measuring the health of open source software ecosystems: Moving beyond the project scope. Information and Software Technology, 56(11):1508-1519, 2014.

19. S. Jansen and M. A. Cusumano. Defining software ecosystems: a survey of software platforms and business network governance. In Software Ecosystems: Analyzing and Managing Business Networks in the Software Industry, chapter 1, 13-28. Edward Elgar, USA, 2013.

20. S. Jansen, A. Finkelstein, and S. Brinkkemper. A sense of community: A research agenda for software ecosystems. In 31st International Conference on Software Engineering Companion Volume, ICSE-Companion 2009, 187-190. IEEE, 2009.

21. C. Jones. Software Assessments, Benchmarks, and Best Practices. Addison-Wesley Information Technology Series. Addison-Wesley Longman Publishing Co., Inc., USA, 2000.

22. J. Knodel and K. Manikas. Towards a typification of software ecosystems. In Software Business, 60-65. Springer International Publishing, 2015.

23. K. Manikas and K. M. Hansen. Software ecosystems - A systematic literature review. Journal of Systems and Software, 86(5):1294-1306, 2013a.

24. K. Manikas and K. M. Hansen. Reviewing the health of software ecosystems - a conceptual framework proposal. In Proceedings of the 5th International Workshop on Software Ecosystems, volume 987 of CEUR Workshop Proceedings, 33-44, Potsdam, Germany, 2013b.

25. J. F. Moore. Predators and prey: A new ecology of competition. Harvard Business Review, 71(3):75-86, 1993.

26. J. F. Moore. The Death of Competition: Leadership and Strategy in the Age of Business Ecosystems. Harper Business, New York, 1996.

27. M. Mäntymäki, and H. Salmela. In Search for the Core of the Business Ecosystem Concept: A Conceptual Comparison of Business Ecosystem, Industry, Cluster, and Inter Organizational Network. In Proceedings of the 9th International Workshop on Software Ecosystems, CEUR-WS, 103-113, 2017

28. D.-S. Oh, F. Phillips, S. Park and E. Lee. Innovation ecosystems: A critical examination. Technovation, 54, 1-6, 2016

29. E.P. Odum, (1966). The strategy of ecosystem development. Science, 164:262-270.

30. M. Peltoniemi, E. Vuori. Business ecosystem as the new approach to complex adaptive business environments. Proceedings of eBusiness Research Forum, 267-281, 2004

31. K. Plakidas, S. Stevanetic, D. Schall, T. B. Ionescu, and U. Zdun. How do software ecosystems evolve? a quantitative assessment of the $\mathrm{r}$ ecosystem.. In Proceedings of the 20th International Systems and Software Product Line Conference (SPLC '16), 89-98, ACM, 2016.

32. M. Seppänen, S. Hyrynsalmi, K. Manikas, and A. Suominen. Yet another ecosystem literature review: $10+1$ research communities. In 2017 IEEE European Technology and Engineering Management Summit (E-TEMS), 1-8, IEEE, 2017

33. A. Suominen, S. Hyrynsalmi, and T. Knuutila. Young mobile phone users: radical and individual — not. Telematics and Informatics, 31(2):266-281, 2014.

34. J. Teixeira, and S. Hyrynsalmi, S. How do Software Ecosystems Co-Evolve? A view from OpenStack and beyond. In Software Business: 8th International Conference, ICSOB 2017, 
Essen, Germany, June 12-13, 2017, Proceedings, 115-130, Springer International Publisher, 2017.

35. S. L. Vargo, and R. F. Lusch. It's all B2b... and beyond: Toward a systems perspective of the market. Industrial Marketing Management, 40(2):181-187, 2011

36. J. West and D. Wood. Evolving an open ecosystem: The rise and fall of the Symbian platform. In Collaboration and Competition in Business Ecosystems, volume 30 of Advances in Strategic Management, 27-67. Emerald Group Publishing Limited, 2013.

37. K. Wnuk, K. Manikas, P. Runeson, M. Lantz, O. Weijden, and H. Munir. Evaluating the governance model of hardware-dependent software ecosystems - a case study of the axis ecosystem. In Software Business. Towards Continuous Value Delivery, volume 182 of Lecture Notes in Business Information Processing, 212-226. Springer International Publishing, 2014 